Conclusion Hybrid angiography-MRI units offer a unique capability to inform neurointerventionalists of the viability of the tissue they are attempting to salvage during complex cerebrovascular interventions. Integrating MRI into the stroke treatment angiography suite may thereby improve individual patient selection and treatment selection.

Disclosures K. Narsinh: None. B. Kilbride: None. K. Mueller: 5; C; Siemens Healthineers. J. Vitt: None. J. Massachi: None. M. Amans: 1; C; NIH. D. Cooke: 1; C; Siemens Healthineers. M. Wilson: None. S. Hetts: 1; C; Siemens Healthineers, NIH. 2; C; Imperative Medical, MicroVention Terumo, Route 92 Medical.

\section{E-165 CAROTID INTRAPLAQUE HEMORRHAGE IS INDEPENDENT OF THE DEGREE OF CAROTID ARTERY STENOSIS AND IS MORE PREVALENT IN SYMPTOMATIC VERSUS ASYMPTOMATIC PATIENTS WITH STENOSIS LESS THAN 70\%: IMPLICATIONS FOR THE UTILITY OF CAROTID PLAQUE IMAGING}

${ }^{1} \mathrm{~A}$ Larson*, '2J Benson, 'G Lanzino, 'W Brinjikji. 'Neurosurgery, Mayo Clinic, Rochester, $M N{ }^{2}$ Radiology, Mayo Clinic, Rochester, MN

\subsection{6/neurintsurg-2020-SNIS.197}

Background The relationship between the prevalence of intraplaque hemorrhage and degree of carotid artery stenosis has not been well established. It is unclear whether there is a threshold of stenosis/plaque progression during which plaque hemorrhage develops within an atherosclerotic lesion.

Methods In this study, we reviewed our institutional case series of patients with carotid plaque imaging and reported on the prevalence of plaque hemorrhage based on degree of stenosis as well as symptomatic status.

Results The presence of plaque hemorrhage was independent of degree of stenosis. This was true among both asymptomatic carotid arteries $(\mathrm{P}=0.31)$ and symptomatic carotid arteries $(\mathrm{P}=0.11)$. For arteries with severe stenosis, there was no

Abstract E-165 Table 1 Degree of carotid artery stenosis and prevalence of intraplaque hemorrhage in all studied vessels

\begin{tabular}{ll}
\hline Degree of Stenosis & $\begin{array}{l}\text { Prevalence of Plaque } \\
\text { Hemorrhage (\%) }\end{array}$ \\
\hline$<30 \%$ & $34 / 944(3.6)$ \\
$30-49 \%$ & $17 / 50(34.0)$ \\
$50-69 \%$ & $34 / 103(33.0)$ \\
$70 \%+$ & $43 / 131(32.8)$
\end{tabular}

Abstract E-165 Table 2 Degree of carotid artery stenosis and prevalence of intraplaque hemorrhage in asymptomatic versus symptomatic patients

\begin{tabular}{llll}
\hline \multicolumn{4}{l}{ Prevalence of Plaque Hemorrhage } \\
\hline Degree of stenosis & Asymptomatic (\%) & Symptomatic (\%) & $P$ \\
\hline$<30 \%$ & $6 / 504(1.2)$ & $17 / 176(9.7)$ & $<0.0001$ \\
$30-49 \%$ & $4 / 28(14.3)$ & $8 / 17(47.1)$ & 0.03 \\
$50-69 \%$ & $6 / 38(15.8)$ & $23 / 52(44.2)$ & 0.009 \\
$70 \%+$ & $10 / 40(25.0)$ & $22 / 69(31.9)$ & 0.52 \\
\hline
\end{tabular}

difference in prevalence of plaque hemorrhage among symptomatic and asymptomatic patients (22/69 versus 10/40, $\mathrm{P}=0.52$ ). However, for arteries with moderate stenosis (30$69 \%$ ) the prevalence of plaque hemorrhage was significantly higher among symptomatic arteries versus asymptomatic (31/ 69 versus $10 / 66, \mathrm{P}=0.0002)$. The same was true for patients with no stenosis $(17 / 176$ versus $6 / 504, \mathrm{P}<0.0001)$.

Conclusions The presence of plaque hemorrhage is independent from the degree of carotid artery stenosis. Carotid Plaque Imaging for detection of plaque hemorrhage is likely most helpful in identifying symptomatic lesions among patients with $<70 \%$ stenosis. Its utility for patients with severe stenosis is less certain.

Disclosures A. Larson: None. J. Benson: None. G. Lanzino: None. W. Brinjikji: None.

\section{E-166 UTILIZATION OF RADIAL ACCESS IN NEUROENDOVASCULAR CASES: A SINGLE-CENTER EXPERIENCE}

K Dakay*, G Kaur, J Santarelli, C Gandhi, F Al-Mufti. Neurosurgery, Westchester Medical Center, Valhalla, NY

\subsection{6/neurintsurg-2020-SNIS. 198}

Introduction Transradial access is increasingly utilized as an alternative to transfemoral access for neuroendovascular procedures; the radial approach has been widely used for cardiac catheterizations and has been shown to have a lower rate of access site complications and overall complications as compared to femoral access. However, there is a steep learning curve with institution of the transradial method including changes in patient positioning, use of the Simmons catheter, and nursing familiarity with closure devices which can often impact the adoption of this method. We demonstrate our single-center experience with widespread adoption of the transradial approach.

Materials and Methods We prospectively collected data from all neuroendovascular cases from October 2019 - February 2020 including site of approach, type of procedure, and crossover rate. We dichotomized procedures into diagnostic and interventional procedures, and further divided by the type of intervention.

All interventional cases were performed via proximal radial access with a 6 French Terumo slender sheath, and either a Benchmark or Infinity guide catheter depending on the vessel of interest, patient anatomy and other features. Diagnostic cases were performed with a 5 French Terumo slender sheath and a 5 French Glide Simmons catheter; distal radial access was used in most diagnostic cases unless anatomical difficulty precluded this approach. Closure devices were used to achieve hemostasis in all patients. A spasmolytic cocktail consisting of lidocaine, nitroglycerin, and verapamil was administered in all cases; heparin was added to the cocktail unless otherwise contraindicated. For distal radial access, the Merit distal radial band was applied and kept in place with $5-10 \mathrm{~mL}$ of air for two hours prior to deflation. For proximal radial access, the Terumo TR band was utilized with up to $20 \mathrm{~mL}$ of air inflated, and kept in place for four hours prior to deflation. Results A total of 387 cases were performed from October 2019 to January 2020, of which 94 were attempted via radial access. 4 cases were excluded due to transfemoral crossover due to patient anatomy, and 90 cases were successfully 


\begin{tabular}{|c|c|c|c|c|c|}
\hline Month & $\begin{array}{l}\text { Total } \\
\text { Cases } \\
\text { (n) }\end{array}$ & $\begin{array}{l}\text { Radial } \\
\text { Cases } \\
\text { (n) }\end{array}$ & $\begin{array}{l}\text { Percent of Cases } \\
\text { with Radial Access } \\
\text { (\% total) }\end{array}$ & $\begin{array}{l}\text { Diagnostic } \\
\text { Radial } \\
\text { Cases(n) }\end{array}$ & $\begin{array}{l}\text { Interventional } \\
\text { Radial cases } \\
\text { (n) }\end{array}$ \\
\hline October 2019 & 87 & 9 & $10.3 \%$ & 9 & 0 \\
\hline November & 78 & 10 & $12.8 \%$ & 6 & 4 \\
\hline \multicolumn{6}{|l|}{2019} \\
\hline December 2019 & 70 & 20 & $28.6 \%$ & 14 & 6 \\
\hline January 2019 & 80 & 23 & $28.8 \%$ & 17 & 6 \\
\hline February 2019 & 72 & 28 & $38.9 \%$ & 24 & 4 \\
\hline
\end{tabular}

performed with radial access, for a total crossover rate of $4.3 \%$. The use of radial access as a proportion of total case volume increased from $10.3 \%$ in October 2019 to $38.9 \%$ in February 2020 (table 1). A total of 20 radial interventional procedures were performed during the time period studied including flow diversion, middle meningeal artery embolization, epistaxis embolization, coiling, and thrombectomy.

Conclusion Our single-center series demonstrates low crossover rates from transradial to transfemoral of $4.3 \%$, and shows that widespread adoption of this method can be successfully achieved in a period of a few months. Although radial access presents its own challenges, it is feasible to perform many diverse neuroendovascular cases by this route.

Disclosures K. Dakay: None. G. Kaur: None. J. Santarelli: None. C. Gandhi: None. F. Al-Mufti: None.

\section{E-167 IMAGING OPTIMIZATION FOR FLOW DIVERSION IN C- ARM CONE BEAM COMPUTED TOMOGRAPHY}

1,2D Dornbos III*, 2,3J DiNitto, 1,2L Elijovich, 1,2D Hoit, 1,2 $\mathrm{V}$ Inoa-Acosta, ${ }^{1,2} \mathrm{C}$ Nickele, ${ }^{4}$ E Duckworth, ${ }^{1,2}$ A Arthur. ${ }^{1}$ Neurological Surgery, Semmes-Murphey Clinic, Memphis, TN; ${ }^{2}$ Neurological Surgery, University of Tennessee Health Science Center, Memphis, TN; ${ }^{3}$ Siemens Medical Solutions, Malvern, PA; ${ }^{4}$ Neurological Surgery, St. Luke's Health System, Boise, ID

10.1136/neurintsurg-2020-SNIS.199

Introduction Contrast usage for Cone Beam Angiographic Computed Tomography (CBCTA) performance has limited efficacy for simultaneous visualization of vasculature, implanted devices, and surrounding tissue. Optimal windowing of CBCTA images in order to simultaneously visualize both low attenuating brain parenchyma and high attenuating flow diverters remains a significant challenge. Appropriate dilution of contrast has the potential to reduce the gray scale value on the vasculature and allow enhanced simultaneous visibility of tissue and parent artery. Currently, there has been limited work done pertaining to optimal contrast dilution in CBCTA. $^{1}{ }^{2}$ We present an in vivo study aimed to identify optimal contrast dilution to improve image quality in the setting of flow diverting stents.

Methods Cone beam CT-based computed angiographic imaging (20 s DR, Syngo DynaCT, Siemens Healthineers, Forchheim, Germany) was performed on 10 patients following placement of a Pipeline (Medtronic USA) flow diverting stent. Cone beam CT imaging was acquired with selective internal carotid artery catheterization utilizing 5 different contrast percentages $(5,10,15,20$, and $25 \%)$ with a constant flow rate of $3 \mathrm{~mL} /$ $\mathrm{sec}$ and $80 \mathrm{cc}$ of contrast. Gray scale values were averaged for pertinent structures (parent artery, Pipeline device, bone, and background) using region of interest (ROI) analysis of respective Hounsfield units. Contrast to noise ratio (CNR) was used for measurement. Contrast dilution that allows matched CNR in both bone and the parent artery provides ideal visualization.

Results In the 10 patients evaluated in this study, evaluation of bone and parent vessel CNR identified 15\% contrast as optimal for visualization of the Pipeline embolization device within the parent artery (figure 1A). Other contrast concentrations had greater observed differences between bone and parent vessel CNR (figure 1B) and decreased visualization of the flow-diverting device.

Conclusion The concentration of contrast administered during Cone Beam Angiographic Computed Tomography has a substantial impact on the attenuation of surrounding structures (bone, parenchyma), which can impair simultaneous visualization of the parent vessel and implanted device. Based on this analysis, $15 \%$ contrast dilution optimizes visualization of the Pipeline embolization device and its position within the parent artery.

\section{REFERENCES}

1. Duckworth, et al., Optimizing contrast-enhanced cone-beam CT protocol to facilitate simultaneous visualization of neurovascular pathologies and surrounding structures of interest. Interventional Neuroradiology 2019;7(1):102-110. 